\title{
Identification and Prioritization of the Factors Affecting the Disaster Preparedness of Schools in Mashhad, Iran
}

\author{
Fatemeh Nejad Shokouhi ${ }^{1} \mathbb{D}$, Zahra Naji Azimi ${ }^{2} \mathbb{D}$, Fatemeh Jame Kordkandi $^{3} \mathbb{D}$
}

Date of submission: 31 May. 2019 Date of acceptance: 19 May. 2020

\begin{abstract}
INTRODUCTION: Iran has always been prone to natural disasters, such as hurricanes and earthquakes, which are followed by heavy financial and bodily harms. In this regard, it is crucial to have disaster management in the schools of Iran to protect the significant number of young people studying in schools. Therefore, school principals must be constantly prepared for disasters and develop disaster management plans.

METHODS: The present study aimed to identify and prioritize the factors that affect the natural disaster preparedness of schools using the fuzzy analytic hierarchy process (FAHP) method. Moreover, another objective of this research was to rank the elementary schools in District 6 of Mashhad regarding their disaster preparedness with the fuzzy technique for order preference by similarity to ideal solution (FTOPSIS). In this research, first, the criteria and sub-criteria for disaster preparedness were obtained using the Delphi method and according to the opinions of experts. Afterward, the collected criteria and sub-criteria were ranked using the FAHP method. The statistical population of this research consisted of experts, including principals and experts in the studied schools (schools in District 6 of Mashhad) who were familiar with disaster management issues. In total, 10 experts were selected as the sample using the purposive sampling method.

FINDINGS: Based on the results, the most important disaster preparedness factors in schools were building retrofit, adherence to basic standards, and committee formation, in that order.

CONCLUSION: Finally, the elementary schools of District 6 of Mashhad were ranked in terms of disaster preparedness using the obtained model and the FTOPSIS. This ranking can help the managers in making decisions to prioritize the conduction of building retrofit of the schools in the studied area.
\end{abstract}

Original Article

Keywords: Delphi Technique; Disaster Management in Schools; Disaster Preparedness; Fuzzy AHP, Fuzzy TOPSIS

How to cite this article: Nejad Shokouhi F, Naji Azimi Z, Jame Kordkandi F. Identification and Prioritization of the Factors Affecting the Disaster Preparedness of Schools in Mashhad, Iran. Sci J Rescue Relief 2019; 11(4): 267-74.

\section{Introduction}

$\mathrm{N}$ owadays, everyone seeks to protect their lives and well-being and develop their personal and social life by trying to overcome or eliminate obstacles that they might face along the way. However, humans as part of the universe are not able to predict everything. Therefore, disasters will always threaten the lives of humans and the continuity of their existence (1).

If we are not properly prepared for disasters, they can severely damage our lives. Organizations, depending on their type of activity, face these

1-PhD Student, Operations Research Management, Faculty of Economic and Administrative Sciences, Ferdowsi University of Mashhad, Mashhad, Iran

2- PhD, Department of Management, Faculty of Economic and Administrative Sciences, Ferdowsi University of Mashhad, Mashhad, Iran 3-BSc Student, Public Administration, Faculty of Economic and Administrative Sciences, Ferdowsi University of Mashhad, Mashhad, Iran Correspondence to: Zahra Naji Azimi, Email: znajiazimi@um.ac.ir 
disasters as well and if they ignore such challenges or do not prepare themselves for dealing with such situations, they will be easily obliterated (1). In short, it can be said that natural disasters have become an integral part of the life of organizations and societies today (2).

The traditional view of disaster management defined it as extinguishing a fire, meaning that disaster managers waited for the disaster to happen and only tried to limit its damages afterward. However, recently its definition has undergone a change. According to the new meaning, a set of practical plans and strategies should be developed for the management of the possible future crises. Moreover, the managers should think about possible disasters and be prepared for them in advance (1).

Iran is located in one of the most earthquakeprone regions of the world; therefore, there is the possibility of destructive earthquakes all around the country. Consequently, it is important to know the seismic nature of this country. Iran is located on one of the two major seismic belts in the world and occasionally has major earthquakes. Since 1961, various and at times destructive earthquakes have caused considerable damages to different parts of the country. In this regard, it is necessary to use the experiences of other earthquake-prone countries that have been successful in the organization of urban affairs and reinforcement of their cities (3).

The main purpose of the development of a disaster management plan is to reduce and minimize the risks of a disaster. Based on the conditions of each community for its educational centers and students, the first step for disaster managers and decision-makers is to provide adequate information for the students (4). Governmental laws do not require schools to have emergency management plans (5). However, if the students are properly informed about and trained for the disasters they might face, they will be better prepared to deal with such situations.

Therefore, when a disaster occurs, the students will know how to deal with it since they have been trained in this regard by their principals and counselors. Moreover, in this way, they will experience the least possible amount of stress. In addition, prepared students can help the search and rescue process happen faster which will reduce the damages (6).
Therefore, it is necessary for school principals to always be prepared for natural disasters and consider ways to prevent or reduce their impacts on the schools. Regarding the importance of this issue, the present article aimed to identify and prioritize the factors that affect disaster preparedness in schools using the fuzzy analytic hierarchy process (FAHP) method and rank elementary schools in District 6 of Mashhad, Iran in terms of disaster preparedness with Fuzzy Technique for Order Preference by Similarity to Ideal Solution (FTOPSIS).

\section{Methods}

The present research is an analytical survey in terms of applied purpose and data collection. The statistical population of this study consisted of principals and experts of the studied schools who were familiar with disaster management issues. In total, 10 experts were selected as the subjects using the purposive sampling method. Moreover, the required data were collected using a Delphi questionnaire and two separate questionnaires for FAHP and TOPSIS methods. Furthermore, library resources were consulted for the data collection as well.

First, 10 questionnaires were completed by the experts to identify the disaster preparedness criteria of the schools. The experts in this research included principals and teachers who were active and involved with the disaster management of the schools. The obtained criteria and their subcriteria were provided for the school principals, who were familiar with disaster management, in order to be ranked using the FAHP technique. Subsequently, the FTOPSIS technique was used to rank the schools based on their disaster preparedness.

\section{A) Delphi method}

In the present study, the Delphi method was used to "identify" and "screen" the disaster preparedness criteria of the schools. Delphi method is not a multiple-criteria decision-making method; however, it was used to screen the criteria or reach a consensus regarding the importance of the decision-making criteria. The Delphi method is defined as a research approach for the achievement of a consensus using a series of questionnaires and the provision of feedback to participants who are experts in the target areas. The Delphi method should be used once for 
Table 1. Criteria and sub-criteria of disaster preparedness in schools obtained by Delphi technique Main criteria Sub-criteria

\begin{tabular}{|c|c|c|}
\hline Main criteria & & Sub-criteria \\
\hline \multirow{8}{*}{ Education } & $\mathrm{E}_{1}$ & $\begin{array}{c}\text { Visits of centers, such as the International Earthquake Research Institute } \\
\text { and the Institute of Geophysics }\end{array}$ \\
\hline & $\mathrm{E}_{2}$ & $\begin{array}{c}\text { Contests for essay, wall newspaper, photo, and cartoon on the subject of } \\
\text { earthquake management }\end{array}$ \\
\hline & $\mathrm{E}_{3}$ & Provision of educational videos about earthquakes \\
\hline & $\mathrm{E}_{4}$ & Organization of workshops on various types of disasters \\
\hline & $\mathrm{E}_{5}$ & First aid training \\
\hline & $\mathrm{E}_{6}$ & $\begin{array}{c}\text { Introduction of safe places, emergency exit routes, how to take shelter, } \\
\text { and how to exit the building }\end{array}$ \\
\hline & $\mathrm{E}_{7}$ & How to use a fire extinguisher \\
\hline & $\mathrm{E}_{8}$ & Performance of earthquake maneuvers \\
\hline \multirow{6}{*}{ Periodic inspection } & $\mathrm{SI}_{1}$ & Periodic inspection of classroom safety status \\
\hline & $\mathrm{SI}_{2}$ & Periodic inspection of laboratory safety status \\
\hline & $\mathrm{SI}_{3}$ & Periodic inspection of library safety status \\
\hline & $\mathrm{SI}_{4}$ & Periodic inspection of the prayer hall safety status \\
\hline & $\mathrm{SI}_{5}$ & Periodic inspection of the schoolyard safety status \\
\hline & $\mathrm{SI}_{6}$ & Become aware of accident statistics provided by the health center \\
\hline \multirow{5}{*}{ Building retrofit } & $\mathrm{I}_{1}$ & School building retrofit \\
\hline & $\mathrm{I}_{2}$ & Schoolyard retrofit \\
\hline & $\mathrm{I}_{3}$ & Provision of safe equipment \\
\hline & $\mathrm{I}_{4}$ & Access to medical records of the individuals \\
\hline & $\mathrm{I}_{5}$ & Usage of new equipment and technology in the building \\
\hline \multirow{3}{*}{$\begin{array}{l}\text { Adherence to the basic } \\
\text { standards when building the } \\
\text { school }\end{array}$} & $\mathrm{S}_{1}$ & Selection of a residential area for building the school \\
\hline & $\mathrm{S}_{2}$ & $\begin{array}{l}\text { Selection of a location for the school that is out of the way of power } \\
\text { cables, main and secondary gas lines, and gas stations }\end{array}$ \\
\hline & $\mathrm{S}_{3}$ & Construction of earthquake-proof buildings for schools \\
\hline \multirow{2}{*}{ Committee formation } & $\mathrm{CB}_{1}$ & Formation of a disaster council in schools \\
\hline & $\mathrm{CB}_{2}$ & Formation of a health council that includes teachers and students \\
\hline $\begin{array}{l}\text { Communication with disaster } \\
\text { management organizations and } \\
\text { institutions }\end{array}$ & $\mathrm{O}$ & $\begin{array}{l}\text { Invitation of earthquake and disaster management officials to exchange } \\
\text { information and find appropriate solutions }\end{array}$ \\
\hline
\end{tabular}

screening and multiple times for prediction in order to reach an agreement (7).

\section{B) FAHP technique}

The traditional analytic hierarchy process does not fully reflect the human thinking style. In other words, fuzzy sets are more compatible with linguistic and sometimes ambiguous human explanations; therefore, it is recommended to use fuzzy sets (8).

In 1996, Chang proposed the extent analysis method in which the numbers were Triangular fuzzy numbers (TFNs) (8). The fuzzy scales used in the FAHP are shown in Table 1.

In the analytic hierarchy process (normal and fuzzy); first, the data must be collected according to their different levels in the decision tree, which is known as modeling. In this stage, the problem and the purpose of the decision are made into a hierarchy of the elements of the decision that interact with each other. Decisionmaking elements include "decision criteria" and "decision options". The analytic hierarchy process requires breaking a problem with several criteria into a hierarchy with various levels. The highest level represents the main goal of the decision-making process and the second level indicates the main criteria that could be broken into sub-criteria with more details at the next level (8).

The steps of the FAHP can be described as the following (8): 
1) Draw a decision tree: At this stage, a decision tree is drawn which includes the decision-making levels.

2) Pairwise comparisons: In this step, in addition to the pairwise comparison of the approved criteria, the options should be compared with each other based on each criterion. Since the pairwise comparison table must be completed by TFNs to be solvable by the FAHP, these tables must also be completed by the fuzzy number of $\mathrm{M}=(\mathrm{L}, \mathrm{m}, \mathrm{u})$.

3) Perform calculations in FAHP: In this step, the $S_{i}$ of each criterion (fuzzy elements) should be calculated using the following formula:

$$
s_{i}=\sum_{j=1}^{m} \tilde{M}_{g_{i}}^{j} \otimes\left[\sum_{i=1}^{n} \sum_{j=1}^{m} \tilde{M}_{g_{i}}^{j}\right]^{-1}
$$

Here, $i$ represents the row number and $j$ indicates the column number. In the above formula, ${ }^{\sum_{j=1}^{m}} \tilde{M}_{g i}^{j}$ represents the TFNs in the pairwise comparison tables.

$$
s_{i}=\sum_{j=1}^{m} \tilde{M}_{g_{i}}^{j} \otimes\left[\sum_{i=1}^{n} \sum_{j=1}^{m} \tilde{M}_{g_{i}}^{j}\right]^{-1}=\left(\sum_{j=1}^{m} l_{j} \otimes \sum_{i=1}^{n} l_{i}, \sum_{j=1}^{m} m_{j} \otimes \sum_{i=1}^{n} m_{i}, \sum_{j=1}^{m} u_{j} \otimes \sum_{i=1}^{n} u_{i}\right)
$$

After the calculation of the $S_{i}$ value, their grade of preference towards each other should be calculated:

The grade of preference of each fuzzy element to the other is calculated using the following formula:

$$
\mathrm{v}\left(\tilde{\mathbf{M}}_{2} \geq \tilde{M}_{1}\right)=\sup \left[\min \left(\tilde{\mathbf{M}}_{1}(x), \tilde{M}_{2}(y)\right)\right]
$$

In general, if we consider $\tilde{M}_{1}$ and $\tilde{M}_{2}$ as two TFNs, their grade of preference is defined as follows:

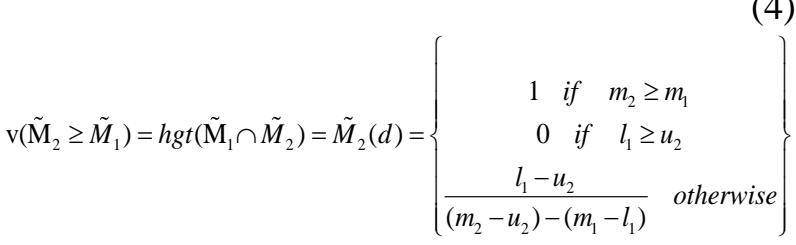

The grade of preference of a TFN to k, another TFN, is also calculated using the following equation:

$V\left(\tilde{\mathrm{M}} \geq \tilde{\mathrm{M}}_{1}, \tilde{M}_{2}, \ldots . ., \tilde{M}_{k}\right)=\operatorname{minV}\left(\tilde{\mathrm{M}} \geq \tilde{\mathrm{M}}_{1}\right), \quad I=1,2, \ldots ., k$

In the extent analysis method, the weight of the criteria in the pairwise comparison matrix is calculated based on the following formula. Now we can calculate $W^{\prime}$ which is the weight of the structures before normalization:

$W^{\prime}\left(s_{i}\right)=\min \left[V\left(s_{i} \geq s_{1}, s_{2}, \ldots, s_{k}\right)\right] \Rightarrow W^{\prime}=\left[W^{\prime}\left(s_{1}\right), \ldots, W^{\prime}\left(s_{n}\right)\right]$

$W^{\prime}$ can be normalized using the following formula:

$W=\frac{W_{i}^{\prime}}{\sum W_{i}^{\prime}}$

If the coefficients of pairwise comparisons of the options are available, the final results will be as follows while $\mathrm{F}$ is the of the options and $\mathrm{W}$ is the weight of the criteria (8):

$$
\underset{(n * 1)}{A}=\underset{(n * n)}{F} \times \underset{(n * 1)}{W}
$$

\section{A) Fuzzy TOPSIS method (9)}

1) Identification of the appropriate evaluation criteria and linguistic variable: Assume that a decision-making committee of $\mathrm{K}$ decision-makers $\left(D^{1}, D^{2}, \ldots, D^{k}\right)$ are responsible for the evaluation of $m$ options $\left(A_{1}, A_{2}, \ldots, A_{m}\right)$ based on $n$ criteria $\left(C_{1}, C_{2}, \ldots, C_{n}\right)$. The criteria are categorized as cost $(\mathrm{C})$ and benefit $(\mathrm{B})$.

2) Creation of a normalized fuzzy decision matrix: According to the explanations of the previous step, the importance or weight of each criterion and the scoring of the options based on each criterion are calculated as follows:

$x_{i j}=\frac{1}{k}(\times)\left[x_{i j}^{t}(+) x_{i j}^{2}(+) \ldots(+) x_{i j}^{k}\right] ; a_{i j}=\sum_{t=1}^{k} a_{i j}^{t} / k ; b_{i j}=\sum_{t=1}^{k} b_{i j}^{t} / k ; c_{i j}^{t}=\sum_{t=1}^{k} a_{i j}^{t} / k$

$w_{j}=\frac{1}{k}(\times)\left[w_{j}^{1}(+) w_{j}^{2}(+) \ldots(+) w_{j}^{k}\right] ; e_{j}=\sum_{t=1}^{k} e_{j}^{t} / k ; f_{j}=\sum_{t=1}^{k} f_{j}^{t} / k ; g_{j}^{t}=\sum_{t=1}^{k} g_{j}^{t} / k$ 
As mentioned above, a fuzzy multi-criteria group decision can be summarized in the following decision matrix:

$D M=\left[\begin{array}{cccc}x_{11} & x_{12} & \ldots & x_{1 n} \\ x_{21} & x_{22} & \ldots & x_{2 n} \\ \cdot & . & \ldots & . \\ x_{m 1} & x_{m 2} & \ldots & x_{m n}\end{array}\right] ; \tilde{W}=\left[w_{1}, w_{2}, \ldots, w_{n}\right]$

In order to ensure compatibility of the mean scores and the mean weights, they should be normalized to become comparable scales. To avoid complexity, linear scales were used to convert scales of different criteria. Finally, the normalized fuzzy decision matrix $(\tilde{U})$ was calculated as follows:

$$
\begin{aligned}
& c_{j}^{+}=\operatorname{Max}_{i} c_{i j} \quad, \quad j \in B ; \\
& a_{j}^{-}=\operatorname{Min}_{i} a_{i j}, \quad j \in C ; \\
& \tilde{u}_{i j}=\left(\frac{a_{i j}}{c_{j}^{+}}, \frac{b_{i j}}{c_{j}^{+}}, \frac{c_{i j}}{c_{j}^{+}}\right), j \in B ; \\
& \tilde{u}_{i j}=\left(\frac{a_{j}^{-}}{c_{i j}}, \frac{a_{j}^{-}}{b_{i j}}, \frac{a_{j}^{-}}{a_{i j}}\right), j \in C
\end{aligned}
$$

According to the above-mentioned normalization method, the range of TFNs is limited to $[0,1]$

3) Creation of a fuzzy weighted normalized decision matrix: The fuzzy weighted normalized decision matrix can be calculated based on the following equation:

$$
\tilde{V}=\tilde{U}(\times) \tilde{W}
$$

\section{4) Determination of fuzzy positive and} negative ideal solutions: The $\tilde{v}_{i j}$ represents a positive normalized TFN and their range is the closed interval of $[0,1]$. The fuzzy positive and negative ideal solutions are:

$$
S^{+}=\left(\tilde{v}_{1}^{+}, \tilde{v}_{2}^{+}, \ldots, \tilde{v}_{n}^{+}\right), \tilde{v}_{j}^{+}=\left(\operatorname{Max}_{i} \tilde{v}_{i j}^{a}, \operatorname{Max}_{i} \tilde{v}_{i j}^{b}, \operatorname{Max}_{i} \tilde{v}_{i j}^{c}\right)
$$

$$
S^{-}=\left(\tilde{v}_{1}^{-}, \tilde{v}_{2}^{-}, \ldots, \tilde{v}_{n}^{-}\right), \tilde{v}_{j}^{-}=\left(\operatorname{Min}_{i} \tilde{v}_{i j}^{a}, \operatorname{Min}_{i} \tilde{v}_{i j}^{b}, \operatorname{Min}_{i} \tilde{v}_{i j}^{c}\right)
$$

5) Final ranking of the options: In this step, the closeness coefficient method was used to rank the options. In this method, the distance of the options from $\mathrm{S}^{+}$and $\mathrm{S}^{-}$was calculated as follows:

$$
\begin{aligned}
& d_{i}^{+}=\sum d\left(\tilde{v}_{i j}, \tilde{v}_{j}^{+}\right) \\
& d_{i}^{-}=\sum d\left(\tilde{v}_{i j}, \tilde{v}_{j}^{-}\right)
\end{aligned}
$$

Here, $d_{i}^{+}$and $d_{i}^{-}$are the distance of each option from the positive and negative ideal solutions, respectively. In this study, the diamond method was used to calculate the distance of each option from the positive and negative ideal solutions:

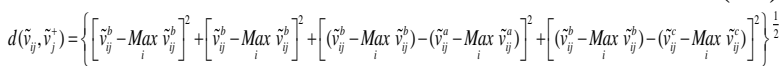

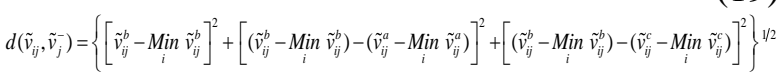

Therefore, to rank the options, their coefficient of closeness was calculated based on $d_{i}^{+}, d_{i}^{-}$, and the following formula:

$$
C C_{i}=\frac{d_{i}^{-}}{d_{i}^{+}+d_{i}^{-}}, i=1,2, \ldots, m
$$

It is clear that if the option $A_{i}$ becomes closer to $\mathrm{S}^{+}$or the positive ideal solution and more distant from the negative ideal solution, the coefficient of closeness will tend to one. Subsequently, the options can be ranked based on the value of the coefficient of closeness. In fact, the options that have a higher coefficient of closeness will also have a higher rank (9).

\section{Findings}

In this section, the results obtained from the implementation of the research steps are analyzed. Initially, using the Delphi method (10) and according to the opinions of the experts, six main criteria with their sub-criteria were introduced, 
which are summarized in Table 1.

In the next step, the criteria and sub-criteria which were identified in the previous step were ranked using the FAHP method. According to

Table 2. Results of the fuzzy analytic hierarchy process for the main criteria of disaster preparedness

\begin{tabular}{cccccccc} 
Education & $\begin{array}{c}\text { Periodic } \\
\text { inspection }\end{array}$ & $\begin{array}{c}\text { Building } \\
\text { retrofit }\end{array}$ & $\begin{array}{c}\text { Adherence to } \\
\text { the basic } \\
\text { standards }\end{array}$ & $\begin{array}{c}\text { Committee } \\
\text { formation }\end{array}$ & $\begin{array}{c}\text { Communication with disaster } \\
\text { management organizations and } \\
\text { institutions }\end{array}$ \\
$\begin{array}{c}\mathbf{C}_{\mathbf{j}} \\
\mathbf{w}\end{array}$ & $\mathrm{C}_{1}$ & $\mathrm{C}_{2}$ & $\mathrm{C}_{3}$ & $\mathrm{C}_{4}$ & $\mathrm{C}_{5}$ & $\mathrm{C}_{6}$ \\
Ranking & 6 & 0.1556 & 0.2077 & 0.1949 & 0.1905 & 0.1854 \\
\hline
\end{tabular}

Table 3. Weight vector of education sub-criteria

\begin{tabular}{cc|ccccccc}
$\mathbf{E}_{\mathbf{j}}$ & $\mathbf{E}_{\mathbf{1}}$ & $\mathbf{E}_{2}$ & $\mathbf{E}_{3}$ & $\mathbf{E}_{4}$ & $\mathbf{E}_{5}$ & $\mathbf{E}_{6}$ & $\mathbf{E}_{7}$ & $\mathbf{E}_{\mathbf{8}}$ \\
$\mathrm{W}$ & 0.0928 & 0.1093 & 0.1231 & 0.1241 & 0.1330 & 0.1433 & 0.1375 & 0.1369 \\
Ranking & 8 & 7 & 6 & 5 & 4 & 1 & 2 & 3 \\
\hline
\end{tabular}

Table 4. Weight vector of inspection sub-criteria

\begin{tabular}{ccccccc} 
SIj & SI1 & SI2 & SI3 & SI4 & SI5 & SI6 \\
W & 0.2844 & 0.2405 & 0.1400 & 0.1405 & 0.1590 & 0.0357 \\
Ranking & 1 & 2 & 5 & 4 & 3 & 6 \\
\hline
\end{tabular}

Table 5. Weight vector of building retrofit sub-criteria

\begin{tabular}{cccccc} 
Ij & I1 & I2 & I3 & I4 & I5 \\
W & 0.3957 & 0.2422 & 0.1866 & 0.1246 & 0.0509 \\
Ranking & 1 & 2 & 3 & 4 & 5 \\
\hline
\end{tabular}

building retrofit, adherence to the basic standards, and committee formation, in that order. In this regard, it is clear that school building retrofit plays a critical role in preparedness.

The weight of each of the sub-criteria is shown in tables 3-7. Among the sub-criteria of education, the introduction of safe places, how to take shelter, the introduction of emergency exit routes, and how to leave had more weight. Moreover, among the sub-criteria of inspection and building retrofit, periodic inspection of classroom safety status and building retrofit had more weight, respectively. Furthermore, among the sub-criteria of standardization, the subcriterion of construction of earthquake-proof buildings for schools had more weight, compared to the other sub-criteria. Besides, among the subcriteria of committee formation, the sub-criteria of formation of a disaster council in schools and a health council that includes teachers and students had the same weights.

Finally, all the elementary schools in District 6 of Mashhad $(n=16)$ were ranked according to their preparedness. This ranking was based on the FTOPSIS and the weights of the criteria and sub-criteria which were obtained using FAHP. The results of this ranking are shown in Table 8 . The names of the schools were: Azadeh, Owj, Payam Noor, Tahzib, Danesh, Razavi, Sherafat, Shahid Pahlavan, Shahid Haeri, Shahid Maghfrati, Saba, Tali'eh Noor, Farhang-e Andisheh, Farhangian, Noor-e Hedayat, and Hejrat. Due to the confidentiality of information, these schools were coded from $\mathrm{A}_{1}-\mathrm{A}_{16}$ in a nonalphabetical order. The results are presented using codes and as shown in Table 10, codes $\mathrm{A}_{3}$ and $\mathrm{A}_{6}$ obtained the highest and lowest ranks, respectively.

The bar chart below also shows the level of disaster preparedness of the schools based on the criteria. For example, the level of preparedness of code $A_{1}$, regarding the education criteria is more than that of code $A_{2}$ and less than that of code $A_{3}$. Similarly, the different criteria of preparedness can be compared using Figure 1 .

Table 6. Weight vector of standardization sub-criteria $\begin{array}{llll}\text { Sj } & \text { S1 } & \text { S2 } & \text { S3 }\end{array}$ 


\begin{tabular}{cccc}
\hline w & 0.2076 & 0.3833 & 0.4091 \\
Ranking & 3 & 4 & 1 \\
\hline
\end{tabular}

Table 7. Weight vector of the committee formation

sub-criteria

\begin{tabular}{ccc} 
CBi & CB1 & CB2 \\
w & 0.5 & 0.5 \\
Ranking & $1 / 0$ & $1 / 0$ \\
\hline
\end{tabular}

Table 8. Distance evaluation, closeness coefficient, and ranking of the schools based on disaster preparedness

\begin{tabular}{|c|c|c|c|c|}
\hline Rank & $\mathrm{CC}$ & d- & $d+$ & $\mathbf{A}_{\mathbf{i}}$ \\
\hline 3 & 0.7086 & 0.0325 & 0.0133 & $\mathrm{~A}_{1}$ \\
\hline 11 & 0.2443 & 0.0101 & 0.0315 & $\mathrm{~A}_{2}$ \\
\hline 1 & 1.0000 & 0.0637 & 0.0000 & $\mathrm{~A}_{3}$ \\
\hline 7 & 0.4350 & 0.0181 & 0.0235 & $\mathrm{~A}_{4}$ \\
\hline 15 & 0.0659 & 0.0035 & 0.0497 & $\mathrm{~A}_{5}$ \\
\hline 16 & 0.0624 & 0.0032 & 0.0484 & $\mathrm{~A}_{6}$ \\
\hline 13 & 0.1779 & 0.0086 & 0.0400 & $\mathrm{~A}_{7}$ \\
\hline 9 & 0.4268 & 0.0160 & 0.0215 & $\mathrm{~A}_{8}$ \\
\hline 14 & 0.1684 & 0.0066 & 0.0326 & $\mathrm{~A}_{9}$ \\
\hline 10 & 0.3845 & 0.0146 & 0.0234 & $\mathrm{~A}_{10}$ \\
\hline 6 & 0.4548 & 0.0172 & 0.0206 & $\mathrm{~A}_{11}$ \\
\hline 5 & 0.6721 & 0.0307 & 0.0149 & $\mathrm{~A}_{12}$ \\
\hline 4 & 0.7048 & 0.0324 & 0.0135 & $\mathrm{~A}_{13}$ \\
\hline 12 & 0.2025 & 0.0100 & 0.0395 & $\mathrm{~A}_{14}$ \\
\hline 8 & 0.4300 & 0.0161 & 0.0214 & $\mathrm{~A}_{15}$ \\
\hline 2 & 0.8648 & 0.0543 & 0.0085 & $\mathrm{~A}_{16}$ \\
\hline
\end{tabular}

$\square \mathrm{E} \backsim \mathrm{SI} \sim \mathrm{I} \backsim \mathrm{S} \backsim \mathrm{CB} \backsim \mathrm{CC}$

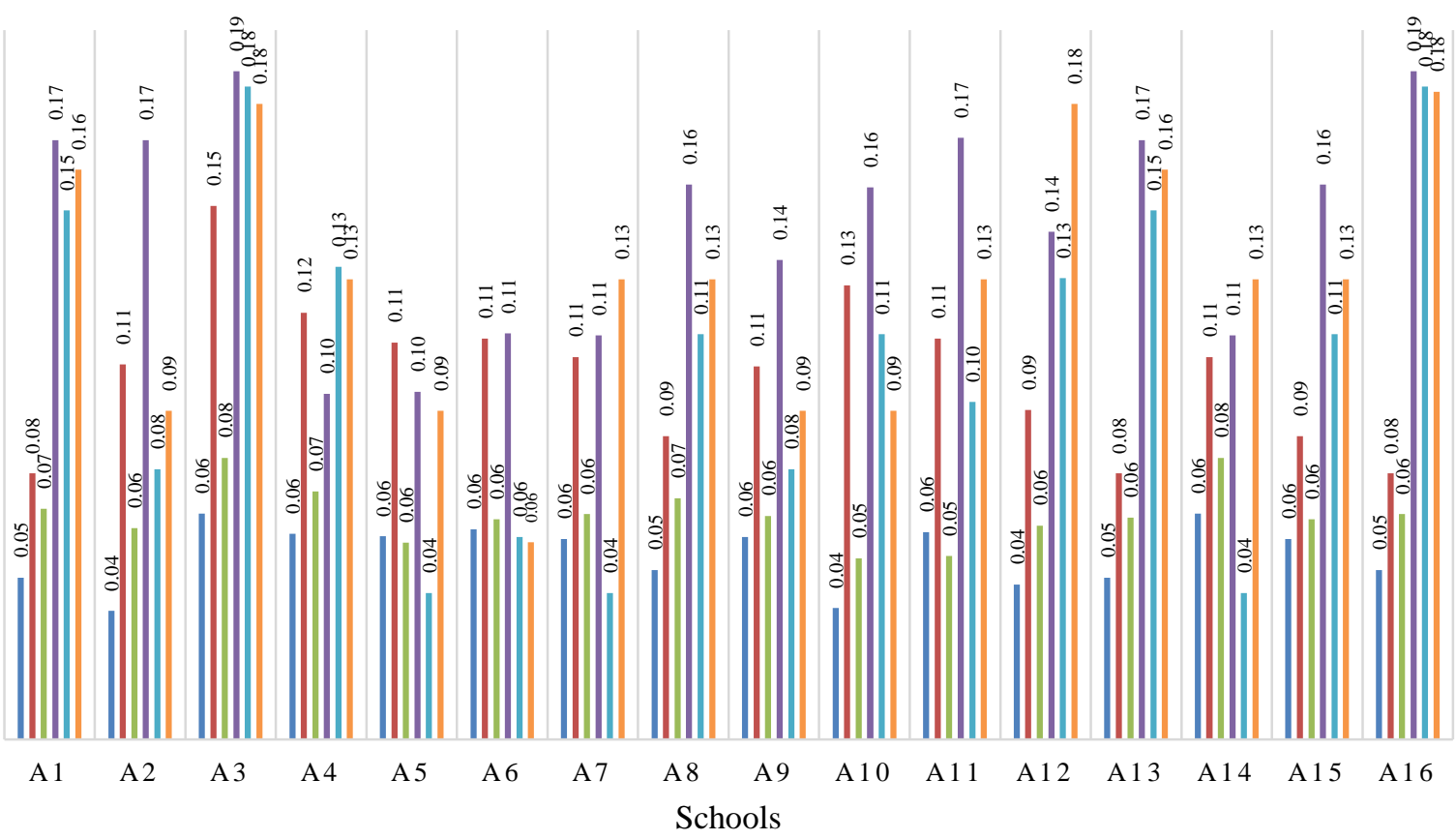

Figure 1. Disaster preparedness of the schools based on the criteria

\section{Discussion and Conclusion}

Given the possibility of natural disasters (e.g., hurricanes and earthquakes), their financial and bodily harms, and the seismicity of the country, disaster management has become even more crucial. In this regard, it is essential to set up disaster management plans, conduct 
building retrofit, adhere to the basic standards, and train individuals and professionals to prepare them for disasters. Therefore, disaster management and preparedness are vital to proper disaster management and damage reduction. Effective disaster management in schools also requires a systematic approach that should be based on awareness, managerial sensitivity, and a good understanding of the importance of careful planning and organizational preparedness (4).

In this study, first, the criteria and sub-criteria for disaster preparedness were obtained using the Delphi method and according to the opinions of experts. Afterward, the criteria and sub-criteria were ranked using the FAHP method. The results revealed that the most important factors for disaster preparedness in schools were building retrofit, adherence to basic standards, committee formation, communication with disaster management institutions and organizations, periodic inspections, and education, in that order. Therefore, it is clear that school building retrofit plays the most vital role in preparedness.

According to the results of FAHP, the most important sub-criterion in terms of building retrofit and compliance with the basic standards were the school building retrofit and, construction of earthquake-proof buildings for schools, respectively. In the case of committee formation, the formation of disaster and health councils, and in the case of periodic inspections, periodic inspections of the safety status of classrooms were of the utmost importance. In the case of the education criteria, the most important sub-criteria were the introduction of safe places and emergency exits, how to take shelter, and how to exit the building.

Moreover, using the FTOPSIS method, elementary schools in District 6 of Mashhad were ranked based on the level of their disaster preparedness. Thereafter, a bar chart was drawn that showed the level of readiness of schools in terms of disaster preparedness criteria. This chart can be used to compare the studied schools based on the preparedness criteria.

\section{Conflict of Interests}

None.

\section{References}

1. Yar Ahmadi Khorasani M. The crisis: an inseparable reality from organizations. Tehran: Management Monthly; 2005. P. 101-2. [In Persian].

2. Rezvani H. Organizational crisis management. Second Conference on Crisis Management in the Building Industry, Isfahan, Iran; 2012. [In Persian].

3. List of earthquakes in Iran. Iran Earthquake. Available at: URL: www.earthquake.ir/index.php? menu=earth_quake_in_Iran; 2019. [In Persian].

4. Mirzaei S. Crisis management at school. Crisis Management. Available at: URL: http://modiriyatbohran.persianblog.ir; 2011. [In Persian].

5. Spillan JE, Crandall W. Crisis planning in the nonprofit sector: should we plan for something bad if it may not occur? Southern Busin Rev 2002; 27(2): 18 .

6. Khodabakhshi M. Familiarity with the concepts of crisis and types of crisis and crisis management. Available at: URL: http://iecatex.blogfa.com/post295.aspx; 2012. [In Persian].

7. Habibi A, Izadyar S, Sarafrazi A. Fuzzy multicriteria decision making. Rasht: Gilles Inscription Publication; 2014. P. 21-2. [In Persian].

8. Zanjirchi M. Process of fuzzy hierarchical analysis. Tehran: Publication of Sanei Shamirzadi; 2011. [In Persian].

9. Chu TC. Selecting plant location via a fuzzy TOPSIS approach. Int J Adv Manufact Technol 2002; 20(11): 859-64.

10. Crisis management. Country Crisis Management Organization. Available at: URL: http://www.ndmo. ir/fa/publictraining/teacher; 2018. [In Persian]. 